\title{
CHANCE, DESIGN, DEFEAT
}

\section{RENÉ VAN WOUDENBERG}

\author{
VU University Amsterdam
}

In his wonderfully wise and witty, sharp and subtle Where the Conflict Really Lies, Alvin Plantinga suggests, among many other things, that beliefs to the effect that this or that has been designed ${ }^{1}$ are typically basic, i.e. that they are not held on the basis of arguments. For instance, upon noticing a watch that lies on the heath, one may form, without engaging in any form of argument, the belief that it displays design (i.e. that 'its parts are framed and put together for a purpose', to use an expression from William Paley's famous discussion). Basic design beliefs aren't only about human-made artefacts. Upon observing the wonderful contrivances for certain purposes in nature, one may form, as Darwin confessed he often did, ${ }^{2}$ without engaging in any form of reasoning, the belief that those items display design. Plantinga maintains not only that design beliefs are typically basic, but also that they can be, and very often in fact are, properly basic, i.e. that there is nothing improper, irrational or otherwise epistemically untoward in holding design beliefs in the basic way. Design beliefs align, in this respect, with perceptual beliefs, memory beliefs and beliefs about other minds, that typically are also held in the basic way, and very often properly so.

\footnotetext{
${ }^{1}$ Like Plantinga, I take it that something is designed provided it is brought about by an agent who intended it to obtain, and the obtaining of which is due to the intention cum causal efficacy of the agent. This clarification starts, so to speak, from the side of the agent. But the clarification could also start from the other side; we could say that something is designed, provided it is not the product of the free play of natural forces, in the way that a hurricane or an avalanche are the product of the free play of natural forces. (This is done in Ratzsch 2001: ch. 1.) These clarifications are by no means completely satisfactory. For what is it for an agent 'to intentionally bring about' something, and what is 'the free play of natural forces'? But although not completely satisfactory, they must suffice for present purposes.

${ }^{2}$ See Campbell (1885: 236-45). I owe the reference to Ratzsch 2003.
} 
Now when exactly is a basic belief properly basic? Plantinga's theory of warrant provides, roughly, the following answer: A basic belief is properly basic when it has warrant in the basic way. And a belief has basic warrant when it is non-inferentially formed by a cognitive faculty that is functioning properly, in the sort of environment for which it was designed (by God or evolution, or both) according to a design plan successfully aimed at the production of true beliefs. In addition, warrant requires, roughly, that the subject has no undefeated defeater for his belief. Also, and this is very rough, it is irrational for a subject to believe something for which she has a defeater that is not defeated.

Defeaters come in two sorts: some rebut, others undercut the target belief. In case the target belief is a basic belief, this pans out as follows. One acquires a rebutting defeater for one's basic belief that $\mathrm{p}$ when one becomes convinced of the truth of a proposition that is incompatible with $\mathrm{p}$ (it entails the denial of $\mathrm{p}$ ). One acquires an undercutting defeater for one's basic belief that $\mathrm{p}$ when one becomes convinced that there is something in the situation in which one formed the basic belief that $\mathrm{p}$ that nullifies or neutralizes the (non-inferential) grounds of that basic belief, i.e. when one has a good reason for thinking that the belief has not been reliably produced. An example, also used by Plantinga, might help. Suppose you form, in the basic way, the belief that there is a sheep in the field. As you come closer, you become convinced that you have mistaken a sheepdog for a sheep and accordingly form the belief that there is a sheepdog in the field. Then you have acquired a rebutting defeater for your original belief. But suppose you didn't come closer, and someone who sees you staring at what you believe is a sheep tells you that very often sheepdogs frequent that field. If you take his words seriously and believe him, you have acquired an undercutting defeater for your original belief.

There is an interesting difference between the two defeaters. In case you have acquired a rebutting defeater for your belief that $\mathrm{p}$, it would be irrational to continue believing p; rationality requires that you (start to) believe not-p. ${ }^{3}$ But in case you have acquired an undercutting defeater for your belief that $\mathrm{p}$, it isn't necessarily irrational to continue believing

${ }^{3}$ Also possible is the following scenario: you believe $\mathrm{p}$ and you come to believe $\mathrm{q}$ equally strongly, and you furthermore see that $\mathrm{p}$ and $\mathrm{q}$ are incompatible. In that situation your belief that $\mathrm{p}$ rebuts your belief that $\mathrm{q}$, vice versa, but it would be irrational for you to believe the denial of $\mathrm{p}$ (or the denial of $\mathrm{q}$, for that matter). Here suspension of belief is the rational response. 
that p. (After all, in the scenario in which you didn't come closer, what you see in the field might, for all you know, still be a sheep.) Having acquired an undercutting defeater for one's belief that $\mathrm{p}$, a whole range of responses might be rational, depending on the strength of the defeater (and the strength of the defeater depends in part on other beliefs that the subject has); the range encompasses near disbelief, grave uncertainty, a severely less firmly held belief, as well as a somewhat less firmly held belief. Undercutting defeaters, Plantinga suggests, come in degrees. ${ }^{4}$

We have design beliefs, but we also have chance beliefs, i.e. beliefs to the effect that something or other is 'due to chance'. Many philosophers and scientists seem to adopt the idea that design and chance are mutually exclusive $^{5}$ and hence that both of the following implications hold:

I1: If $\mathrm{X}$ is designed, it cannot be chancy (i.e. cannot be a chance event, nor the product thereof).

I2: If $\mathrm{X}$ is chancy, it cannot be designed.

In terms of defeaters these implications tell us that design beliefs are defeaters for chance beliefs, and vice versa. The main task for this paper is to investigate whether this is correct. First I investigate whether or when design beliefs are defeaters, either rebutting or undermining, for chance beliefs. Second I investigate whether or when chance beliefs are defeaters for basic design beliefs. In the course of the discussion the notion of 'chance' will be elucidated.

\section{DESIGN BELIEFS AS DEFEATERS FOR CHANCE BELIEFS}

Let us first consider a couple of cases in which someone holds a chance belief and subsequently acquires a design belief, in order to see whether the latter really rebut or undercut the former. Suppose you are on vacation in Austria, and while roaming Vienna, you bump in on your old high school class mate Harry, whom you haven't seen for years. You are, of course, surprised by this event, unexpected and remarkable as it is, and you find yourself believing it is chance event. It is not implausible to think that what your belief amounts to is that the event bumping in on Harry in Vienna is a chance event, so an event that has the property of being chancy. Now this property, rather obviously, is a relational property,

${ }^{4}$ Plantinga (2011: 252).

${ }^{5}$ See Dawkins 1986, Dembski 1998. 
for the event isn't unexpected and remarkable as such (or intrinsically), but unexpected and remarkable for you. But this means that the event that is chancy (in the sense intended) for you, need not be chancy for someone else. It need not be, for instance, for Harry himself. He might have been scheming to get in contact with you in a way that you wouldn't expect. So long as it isn't revealed to you that Harry has been scheming to see you, you will continue to believe the meeting was a chance event. Your belief involves the following notion of chance:

Chance $_{1}=$ the relational property of being remarkable for and unexpected by someone who is unaware of anyone bringing about the remarkable and unexpected event.

It is clear that chance ${ }_{1}$ and design are compatible, so that neither I1 nor I 2 are true if the notion of chance in them is chance . $_{\text {. }}$

Suppose now that after some time Harry reveals to you that he had been scheming to meet you in Vienna and you acquire the belief that Harry plotted the event. Would that constitute a defeater for your chance $_{1}$ belief? It certainly would. For after Harry's revelation you are aware of someone scheming for the remarkable and unexpected event, hence, unless you have a defeater for your defeater, you can no longer rationally believe that the meeting is $\mathrm{chancy}_{1}$, for you have a defeater for that belief - a rebutting defeater. (A defeater for this defeater would be your belief that Harry's revelations are generally false. If you have that belief, you can rationally continue believing the meeting in Vienna was a chance event.)

But not all uses of 'chance' are specified by Chance $_{1}$ as the following case bears out. Suppose McBride idly shakes two dice, nothing is at stake, and he throws 'snake eyes'. This outcome is in no way remarkable or unexpected. Of course, he expected some outcome, but as snake eyes is as likely an outcome as any, he didn't expect (or not-expect) it more or less than any other. So we may say that the outcome is not chancy. What is correct, though, is that the outcome was unpredictable, i.e. prior to throwing unknowable. Unpredictable outcomes are sometimes called chance events. Throwing snakeeyes is a chance event in this sense-and this is what McBride believes. But now suppose there is a Laplacian Intellect that fully knows the botching of the dice in McBride's hand, the impulse they have upon leaving his hand, the physical properties of the surface on which they are thrown, the collision laws, etc. That Intellect could predict the outcome (at least if we assume determinism - something Laplace 
did assume). What is unpredictable for McBride, isn't unpredictable for a Laplacian Intellect. (Karl Popper was right when he said that when we call the event of throwing dice a chance event, we thereby indicate our ignorance of laws and initial conditions. ${ }^{6}$ Hence, the notion of chance at hand, like Chance ${ }_{1}$, is person relative.

Suppose now McBride sees someone throwing snake eyes and accordingly forms the belief that the outcome is chancy. Suppose next that the person who threw the dice reveals himself as the Laplacian Intellect and furthermore tells McBride that he intended to throw snake eyes and brought it about. ${ }^{7}$ Then McBride will, assuming he has no good reasons for thinking no such Intellect exists, or that that the Intellect is misleading him, form the belief that someone plotted for this event that was unpredictable for him. This belief would constitute a defeater for his initial chance belief - a rebutting defeater. It would be irrational for him, after the Intellect's revelation, to continue believing that the snake eyes outcome is chancy in the following sense:

Chance $_{2}=$ the relational property of being unpredictable for someone who is not aware of anyone intentionally bringing about the unpredictable event.

(I will comment on the second part of this definition in a moment.) It is clear that if an event is chancy, it can at the same time be designed, and hence that I1 and I2 are false for this notion of chance as well.

There are notions of chance still other than Chance $_{1}$ and Chance ${ }_{2}$. Let us see how beliefs involving any of these fare, once the person holding such a belief acquires a design belief.

Shakespeare and Cervantes died on the very same day. Someone who relates this coincidence (as Aristotle would have called it), could do so by using the words: 'By chance, Shakespeare and Cervantes died on the same day.' If Shakespeare and Cervantes had killed each other in a duel, or when a poetry hater bent on eradicating poets from the surface of the earth had shot both men on the same day, or when God, by whatever means, brought about these joint deaths, their dying on the same day would not be a chance event. Furthermore, if it were a law of nature that poets with the sorts of properties that Cervantes and Shakespeare have die on the same day, just as it is a law of nature that water freezes when

${ }^{6}$ Popper (1968: 205).

7 There is a good question about this example that I won't go into now, viz. can a Laplacian Intellect intentionally do something if determinism is true? 
the temperature sinks below 0 degrees Celsius, their deaths would not be chancy in the sense intended either. Saying they died on the same day by chance, then, is saying that their deaths are not brought about by a human or non-human agent who intended them to happen, nor necessitated by a law of nature. We may note that this notion of 'chancy' is not person relative, as it makes no sense to say that an event is chancy in this sense 'for' you, but not 'for' your neighbour. What we have, then, is a third notion of chance:

Chance $_{3}=$ the non-relational property of not being intentionally brought about by a human or non-human agent, nor being necessitated by a law of nature.

When we return to I 2 with Chance $_{3}$ in mind, we can see that it is true. If an event is chancy $_{3}$, it cannot be designed. Let us see how this work out in terms of defeaters.

Suppose that Jan believes that Cervantes's and Shakespeare's dying on the same day was a chance ${ }_{3}$ event. Then it is easy to see that by believing any of the following Jan would have acquired a defeater for her chance belief, viz. (i) Cervantes and Shakespeare killed each other in a duel, (ii) Cervantes and Shakespeare were killed by a poetry hater on the same day, (iii) God saw to it that Cervantes and Shakespeare died on the same day. All of these are rebutting defeaters. But what would be an undermining defeater for her chance belief? This would be a belief to the effect that, for all she knows, (i), (ii) or (iii) is true. That is, all she needs to believe is that it is epistemically possible that any one of these propositions is true. Now we have very good reasons to think that (i) and (ii) are not epistemically possible: we know them to be false. But we don't have those sorts of reasons for (iii) - that proposition may be true; it certainly isn't the case that we know it to be false. We don't know that it is false because God's existence is epistemically possible, and so is the existence of divine reasons for seeing to it that Cervantes and Shakespeare died on the same day. What holds for Jan's chance ${ }_{3}$ belief, can be generalized. When people believe that $\mathrm{X}$ is chancy ${ }_{3}$ and furthermore notice (and hence believe) that it is epistemically possible that God exists, as well as that it is epistemically possible that God has reasons for seeing to it that X exists (or comes about, or happens), they thereby have acquired an undermining defeater for their chance ${ }_{3}$ belief.

${ }^{8}$ Simpson (1949: 93); Beatty (1984: 186). 
In evolutionary biology mutations are oftentimes qualified as random, other times they are characterized as (products of) chance events. Saying that mutations are chancy, has been explained in various ways, for instance as occurring regardless of the organism's needs, ${ }^{8}$ or occurring independent of what is advantageous for the organism'soff-spring. ${ }^{9}$ The notion of chance that is used here is non person relative. Even if neither you, nor any other human being existed, a mutation could still be chancy in this sense (although there would be no one around to call it chancy). Hence, when we say that a mutation is chancy (or random), we ascribe to it the following property

Chance $_{4}=$ the non person relative property of not being caused by the organism because of any possible beneficial effects it might have for its offspring.

With respect to I2 we may note that it is false if the notion of chance in it is chance ${ }_{4}$. We can see this in some detail as follows. Suppose Theodozius believes that this particular mutation $\mathrm{M}$ is chancy ${ }_{4}$ and subsequently comes to believe that $\mathrm{M}$ is divinely created. Has he thereby acquired a defeater for his chance belief? He has not, for, and here I entirely agree with Plantinga (although he uses somewhat different terms ${ }^{10}$ ), a mutation's being chancy ${ }_{4}$ is compatible with that mutation's being caused by God. It is, of course, possible, in theory, that Theodozius acquires a defeater for his chance ${ }_{4}$ belief. A rebutting defeater would be evidence to the effect that organisms do cause mutations because of the possible beneficial effects they may have for their offspring. An undercutting defeater for his belief would be evidence to the effect that the evidence that has been marshalled in favour of his chance belief, is polluted, or seriously incomplete. My point is that although Theodozius' chance belief can, in principle, meet with a defeater, his theistic design belief is not one of them. The belief that mutations are divinely caused doesn't constitute a defeater for the belief that mutations are chancy . $_{4}$ Some chance beliefs involve yet another notion of chance. Laplace held that there is no chance in nature. This fact, he thought, makes it possible for the Laplacian Intellect to predict all future events. But what exactly is it that nature lacks according to Laplace when it lacks chance events? It is this: it lacks events that are without physical causes, i.e. that are physically undetermined. A chance event, in his sense of the word, then,

${ }^{9}$ Sober (1984: 105).

${ }^{10}$ Plantinga (2011: 12). 
is an event that lacks a physical cause. It seems clear that this notion is not person relative. So here we have

Chance $_{5}=$ the non relational property of being physically uncaused. There is an issue as to whether the property of chance ${ }_{5}$ is ever instantiated. Laplace, of course, thought not. But in 1927 Heisenberg enriched physics with the Principle of Uncertainty, one explanation of which is that quantum events such as the emission of a photon are such that they are not determined by antecedent physical conditions: there are no necessary and sufficient physical conditions such that if they obtain, the quantum event will take place. On this explanation such events are chancy $_{5}$, which is sometimes also called 'deep chance'.

Suppose now that Nils, who believes that a certain quantum event is deeply chancy, comes to believe that, somehow, God is the creator, sustainer and ruler of the universe. Has he thereby contracted a defeater for his chance ${ }_{5}$ belief? He has not, or not necessarily. The point is, of course, that a chance ${ }_{5}$ event is an event that has no physical causes. But Nils might assume that there are causes other than physical causes. He might believe, for instance, that there are agent causes, and furthermore that God is the prime agent cause in the universe. He might furthermore take up Plantinga's suggestion that from a theistic perspective quantum events may be interpreted as agent-caused by God. ${ }^{11}$ So, if Nils also believes in divine agent causation, his belief that God is the creator, sustainer and ruler of the universe is no defeater for his chance ${ }_{5}$ belief. (I add that it would be an odd combination of views if Nils were to believe that certain quantum events are deeply chancy, and furthermore believe that God, somehow, rules the universe, but not believe in divine agent causation. For it would certainly seem that belief in God's creating, sustaining, and ruling the universe entails divine agent causation. But if this entailment could sensibly be denied, this might mean that Nils would have a defeater for his chance belief.)

This all goes to show that $\mathrm{I} 2$ is false if the operative notion in it is Chance $_{5}$. It is false that if an event is chancy ${ }_{5}$ it cannot be designed.

\section{CHANCE BELIEFS AS DEFEATERS FOR DESIGN BELIEFS}

Let us now turn the tables and imagine William who holds the basic design belief that the mammalian eye was created (and so designed)

${ }^{11}$ Plantinga (2011: 113-121). 
by God. Which beliefs involving chance could constitute a defeater for his belief? Let us start with the relational notions of chance. Suppose William comes to believe that the mammalian eye, or its emergence, is something remarkable and unexpected by him, so is chancy. Then this belief won't constitute a defeater for his design belief. The same is true if he acquires the belief that the eye's emergence was unpredictable for him, so is chancy $y_{2}$ : this belief is not a defeater for his design belief. Chance beliefs involving relational concepts of chance are no defeaters for design beliefs. This conclusion was already reached earlier on when I argued that for Chance $_{1}$ and Chance ${ }_{2}$, implication I1 is false. Let us next turn to the non-relational concepts of chance.

Were William to acquire the belief that the mammalian eye is chancy $_{3}$, so not intentionally brought about by a human or non-human agent (nor necessitated by a law of nature), then that belief would constitute a rebutting defeater for his design belief. Now on what basis could William acquire this belief? One possibility is that he picked up the idea from reading Richard Dawkins' The Blind Watchmaker in which it is argued that contemporary evolutionary science 'reveals a universe without design. ${ }^{12}$ But if William subsequently were to read Plantinga's discussion of the argument, he would acquire a defeater-defeater. For, as Plantinga convincingly argues, Dawkins' argument shows at best that 'given a couple of assumptions, ... it is not astronomically improbable that the living world was produced by unguided evolution and hence without design'. He continues by saying that 'the argument form " $p$ is not astronomically improbable, therefore p" is a bit unprepossessing, ${ }^{13}$ which is, of course, a marvellous understatement. And so, William's design belief stands undefeated. What this little discussion does show, however, is that if we take I1 to be concerned with $\mathrm{Chance}_{3}$, it is true. If something is designed, it cannot be chancy . $_{3}$

Suppose now that William has the basic belief that human beings are created, so designed, by God. And suppose furthermore that he gets a good college education and learns that human beings have evolved from non-human ancestors through a process that involves random genetic mutation, so through a process that involves chance ${ }_{4}$. Has he thereby acquired a rebutting defeater for his design belief? No, he has not, for, as indicated earlier on, the chance property at hand is the mutation's

\footnotetext{
12 As the subtitle of Dawkins 1986 has it.

${ }^{13}$ Plantinga (2011: 24-5).
} 
property of not having been caused by the organism because of any possible beneficial effects it may have for its offspring. But a mutation with that property can, of course, be caused by God. So the fact, assuming it is a fact, that evolution involves chance ${ }_{4}$, is not a rebutting defeater for the belief that evolved human beings (or any other creatures, for that matter) are created by God. And this means that I 2 conceived of as concerning Chance ${ }_{4}$ is false. William's basic belief that humans are created by God meets no rebutting defeater when he comes to believe that humans have evolved through a process that involves chance ${ }_{4}$. (Of course, had William believed that God created human beings in the way young earth creationists believe he did, then his belief that human beings have evolved from non-human ancestors through a process that involves chance $_{4}$, would constitute a defeater for that particular design belief. But this does not invalidate the point just made, which could also be formulated by saying that chance ${ }_{4}$ belief is no rebutting defeater for what could be called basic 'bare' design belief.)

Finally, assume again that William has the basic belief that humans are divinely designed. If upon reading Jacques Monod's Chance and Necessity he comes to believe that humans have evolved through a process that involves mutations, and that mutations are (the products of) quantum events, so are chancy $_{5}$, i.e. such that no necessary and sufficient conditions for their occurrence exist, has he thereby acquired a defeater for his design belief? No he has not. For by believing that humans are designed by God, he has committed himself to the belief that there is an agent cause (in contrast with an event cause). And what is chancy, may very well be agent caused by God. This is why I1, conceived of as involving Chance $_{5}$, is false too.

I round off by pointing out that the discussion in this section is limited in at least one important respect: it only discusses possible defeaters for basic design beliefs that involve chance. It does not discuss possible defeaters for design beliefs that involve notions other than chance, such as evil and bias. And such possible defeaters have been proposed in the literature. It has been argued, for example, that basic design beliefs about natural objects find defeaters in the evils of animal suffering and also in a cognitive bias to the effect that humans are prone to see design where there is none. Given the limited task set for this paper, however, this was inevitable, and a fuller discussion of these possible defeaters must await another occasion. 


\section{CONCLUSION}

My conclusion, then, is that the implications I1 and I 2 do not, in general, hold. Furthermore, it isn't, generally speaking, true that one's chance belief finds a defeater in design, nor is it, generally speaking, true that one's basic design belief finds a defeater in chance. ${ }^{14,15}$

\section{BIBLIOGRAPHY}

Beatty, John. 1984. 'Chance and Natural Selection', in Philosophy of Science, 51 (2): 183-211

Campbell, George Douglas, 8th Duke of Argyll. 1885. 'What is Science?', in Good Words

Dawkins, Richard. 1986. The Blind Watchmaker: Why the Evidence of Evolution Reveals a Universe Without Design (New York and London: Norton)

Dembski, William B. 1998. The Design Inference (Cambridge: Cambridge University Press)

Popper, Karl R. 1968. The Logic of Scientific Discovery (3d ed., London: Hutchinson)

Plantinga, Alvin. 2011. Science, Religion, Naturalism: Where the Conflict Really Lies (Oxford: Oxford University Press)

Ratzsch, Del. 2003. 'Perceiving Design', in Neil A. Manson (ed.), God and Design: The Teleological Argument and Modern Science (London: Routledge), pp. 125-145

Ratzsch, Del. 2001. Science, Nature, Design (Albany, NY: SUNY Press)

Simpson, George Gaylord. 1949. The Meaning of Evolution (New Haven: Yale University Press)

Sober. Elliott. 1984. The Nature of Selection (Cambridge, Mass.: MIT Press) Van Woudenberg, René \& Jeroen de Ridder. 'Design Scepticism', unpublished

${ }^{14}$ In van Woudenberg \& de Ridder unpublished, we argue for an even stronger conclusion, viz. that design claims cannot be refuted and are, dialectically speaking, in the same boat as radical sceptical hypotheses.

${ }^{15}$ For discussion and comments I am indebted to Jeroen de Ridder, Rik Peels, Emanuel Rutten, and Joëlle Rothuizen-van der Steen. It is thankfully acknowledged that work on this paper was made possible by a grant from the Templeton World Charity Foundation. 